\title{
Persistent controversies about the neolithic revolution
}

\begin{abstract}
The Neolithic Revolution describes the transition from hunting and gathering to farming and then to the onset of agrarian societies. This process, which relied mainly on the domestication of wild plants and animals, occurred independently in at least seven parts of the world from 10,000 BC. It is widely agreed that the shift from a total reliance on wild resources to the use of domesticated foods led to a number of fundamental and far-reaching changes in human society. However, even eight decades after Childe's (1936) seminal publication, the Neolithic revolution continues to lead to major debates and controversies among scholars. It is the purpose of this paper to present and critically evaluate these major debates. The latter are related to the presumed superiority of farming over foraging and to the speed of the transition process. They also concerned the origins of agriculture, the respective role of nature and culture in explaining the economic development, and the mechanisms bringing about the spread of agriculture.
\end{abstract}

Keywords: hunter-gatherer, foraging, farming, neolithic transition, biogeographic conditions, institutions, agriculture diffusion, european neolithization process
Volume I Issue 2 - 2017

\author{
Serge Svizzero \\ Faculté de Droit et d'Economie, Université de La Réunion, \\ France
}

Correspondence: Serge Svizzero, Faculté de Droit et d'Economie, Université de La Réunion, France, Tel +262 26213 82 58,Email serge.svizzero@univ-reunion.fr

Received: February 28, 2017 | Published: May 16, 2017

\section{Introduction}

The transition from hunting and gathering to agriculture has long been regarded as one of the most important development in human history. At its roots was the shift from the reliance on wild plants and animals to domesticated plants and livestock. Domestication is the process by which humans are able to control the reproduction of plants and animals species and thus select for various desirable characteristics. Domestication first occurred in the Levant, around $10,000 \mathrm{BC}$ and it marks the beginning of the archaeological period known as the "Neolithic". From the Near East, farming spread across Europe between 8,500 and 4,000 years ago. However, the adoption of domestic plants and animals is only a single symptom of a major societal and economic transformation. Indeed, people changed their views of many things during the Neolithic period, including the returns expected from their quest of food, acceptable levels of risk, their ability to change their environment, residential stability and property rights, definitions of kinship and residential groupings and the benefits of having more children. Most of these changes find their roots in the Mesolithic period, when solely hunter-gatherers (HG) were living, but they came together during the Neolithic to produce a dramatic change in society.

Because the transition to agriculture encompasses a wide range of causes and consequences that are themselves multidimensional (economic, social, ecological, institutional, technical) its study has led to discussions and to some major debates and controversies among scholars. It is the purpose of this paper to present and critically evaluate these major debates. The first one is about the transition process itself; it has long been considered that, compared to the huntinggathering lifestyle, the shift to agriculture was associated with many advantages and therefore was obvious. However, according to recent studies, the presumed superiority of the farming lifestyle - in the early ages of agricultural development - over foraging has been seriously questioned. ${ }^{1-3}$ The second one is also related to the transition process. It has long been assumed, following the seminal work of Childe (1936) and the terminology he used the so-called "Neolithic revolution" - that the transition was rapid and radical. During the last decades this view has been challenged by various archaeological records and studies. The transition revealed indeed as a gradual and long-term process, with a mixed-economy (based on foraging and farming) during millennia and even temporary reversion to hunting and gathering lifestyle. ${ }^{4,5}$ The third debate is about the main theories explaining the transition to agriculture. Chronologically, those related to push factors such as climate change or population pressure were favored in the literature. ${ }^{5}$ However in the recent decades, theories related to pull factors such as social competition and feasting have been considered separately or side by side with the previous ones. The most recent of these pull explanations, based on the human management of the environment (more specifically on Niche Construction Theory) and the role of property rights has an increasing audience. ${ }^{6,7}$ When the Neolithic transition is considered as a special event on a much larger scale of time its study becomes intrinsically embedded in a fourth debate, the one about the origins of economic development. Two main views are present in the literature associated with this debate: one is focusing on the role of natural resource endowments, geographic and Biogeographic conditions; the other emphasizes the importance of institutions. The last debate is about the diffusion of agriculture from its original center to areas occupied by indigenous hunter-gatherers. The migrationist approach was initially dominant in the literature ${ }^{8,9}$ then it has been challenged by the cultural diffusion. More recently, both approaches have been combined in the integrationist approach which seems a more convincing theory since it fits better with archaeological records, at least for South-East, Central and Northern Europe. ${ }^{10,11}$

The paper is organized as follows. In section 2, it is shown that the presumed superiority of agriculture in its early ages was far from obvious and that hunting-gathering societies were highly resilient to external shocks. Section 3, explains that the transition to agriculture based on domestication and multiple technical innovations was therefore a gradual process over the long-term rather than a true 
(Neolithic) revolution. The main models about the origins of the Neolithic transition are detailed in Section 4, be they related either to push factors, or to pull factors, or to an admixture of both. In section 5 are presented and then compared the two main views about the origins of economic development, one focusing on natural endowments and the other on the role of institutions. The mechanisms bringing about the spread of agriculture are analyzed in section 6 , with special attention for the diffusion of agriculture to Europe from the Near-East. Section 7 concludes.

\section{The presumed superiority of agriculture in its early ages}

It is often believed that the initial effect of the shift from huntinggathering to agriculture was an immediate increase of the amount of food production. Societies that adopted agriculture were able to produce far more food in a given territory than those that relied on foraging. This increase in productivity could be used either to expand the economic surplus or expand population, with both usually occurring. However, recent studies have deeply challenged this vision demonstrating that compared to foraging, agriculture in its early ages was an activity with low return and that farmers were incurring high risks.

\section{The low attractiveness of the farming way of life}

In Mesolithic Europe, for example and as illustrated by the Ertebølle ${ }^{1}$ culture, HG were not mobile and nor were they organizationally simple. On the contrary, they tended towards socioeconomic complexity, including sedentism. Similarly Neolithic European farmers as illustrated by the $\mathrm{LBK}^{2}$ culture were not superproductive and sedentary. On the contrary, they were often mobile and had a mixed-economy, i.e. an economy combining hunting-gathering and farming. The cultural diffusion of the Neolithic revolution i.e. the deliberate choice of HG to switch to agriculture, finds therefore little support. Moreover, it was often believed that farmers were affluent and HG was poor. From the 1960s, the latter part of this vision was challenged by the results of ethnological studies ${ }^{12}$ of HG societies. Indeed, it appeared that some modern HG societies (mainly! Kung and Hadza, both located in Africa) were very different from the usual description of HG societies. Indeed, these societies did not experience scarcity of food and individuals had to do little work to satisfy their limited ends. Therefore, they were labeled as the "original affluent society". ${ }^{13}$ Thus, the former part of the vision mentioned above has also been challenged. The first agriculturalists are now believed to have put in more rather than less labor to attain subsistence. As pointed out by ${ }^{14}$ "Traditional scholarship has regarded farming as highly desirable. Scholars of human history long assumed that once humans recognized the impressive gains from cultivation and domestication, they would immediately take up farming. However, more recent studies have indicated that early farming was indeed back breaking, time consuming and labour-intensive". ${ }^{1}$ Also asked "Why farm? Why give up the 20-hour work week and the fun of hunting in order to toil in the sun? Why work harder, for food less nutritious and

${ }^{1}$ The Ertebølle culture is the name given to the Late Mesolithic/Early Neolithic communities of Northern Europe - South Scandinavia, dated between 5400 $3900 \mathrm{BC}$, consisting of fisher-hunter-gatherers who adopted pottery but not agriculture from their neighbors.

${ }^{2}$ The Linearbandkeramik Culture (also called Bandkeramik or Linear Pottery Ceramic Culture or simply abbreviated LBK) is the first true farming communities in Central Europe, dated between about 5400 and 4900 BC. a supply more capricious? Why invite famine, plague, pestilence and crowded living conditions?"

In other words, early agriculturists had to work more hours than foragers did. They were also more prone to lethal disease and malnutrition, ${ }^{15}$ as a result of the shift towards dependence on one or a few domesticated plants, with a diet based predominantly on complex carbohydrates. Increasing sedentism and living in close proximity to domestic animals led to poor sanitation and an increase prevalence of zoonotic disease. They also had to endure less egalitarian social structures than hunter-gatherer societies. Since there are almost no indications of increased standards of living immediately after the agricultural transition, why complex HG should have decided to give up their way of life in order to adopt agriculture?

The low attractiveness of agriculture is also confirmed by some cases of reversion from agriculture to hunting and gathering, depending on opportunity costs. Some examples of reversion are well documented in Northern America ${ }^{4}$ as well as in other regions. ${ }^{16}$ Indeed in North America the (re)-introduction of horses by conquistadors caused some north-American native Indians tribes ${ }^{3}$ to revert to hunting as a permanent way of life. Another example of reversion concerns the Levant and is about the well-known Natufians. Indeed, it appeared that the late Natufians reverted to a higher degree of mobility after having adopted a settled life. Decreases in site size, the decline of architecture, as well as changes in the burial record have been seen as indicators of increased mobility. It is suggested that the reason for higher mobility during the late Natufian was the climatic deterioration which occurred with the onset of the Younger Dryas, which depleted available resources. This in turn, resulted in a dispersal of populations across the region to maximize their returns from different areas and alleviate risk.

\section{Adaptation and resilience of hunter-gatherer societies}

Traditional climate forcing models ${ }^{17}$ intended to explain the origins of agriculture in the Near-East proposed that the shift to wild cereal cultivation was a solution to the failure of foraging systems driven by the terminal Pleistocene Younger Dryas climatic deterioration. In doing so, they assumed that the Neolithic revolution was a response to the earliest well-documented example of social collapse i.e. to the failure of foraging economies in the wake of abrupt climatic change. However, this view has been challenged ${ }^{18}$ in the case of HG societies living in the Levant - by assuming that climatic fluctuations leading to major restructuring of vegetation only resulted in a shift in resource focus of HG rather than forcing a collapse of foraging economies. Indeed the Levant is within the Mediterranean climatic zone where vegetation zones are complex: woodlands dominated the west and the north while grasses and other steppic plants are present in the east and the south. In this context, the vegetation responds to climatic changes by shifts in boundaries and shrinking or expanding within their respective zones. In other words, HG subsistence systems in the Levant were highly adaptable and resilient and robust in terms of diversity of options and the mobility of HG. HG societies had a broad range of economic strategies that enhanced their resilience. In difficult times, they may have had to extend what they foraged to include low ranked resources. ${ }^{19}$ This foragers' adaptation has been labeled by Flannery $\mathrm{KV}^{20}$ "the broad-spectrum revolution". In the late Pleistocene or early Holocene, low-level pre-domestication cultivation may have occurred and would have been one of many options available to foragers. It

${ }^{3}$ Cheyenne, Arapaho and Pawnee. 
is only until well in the Holocene that cultivation had a significant impact on foraging economies. Moreover, long-term social memory of accumulated experiences was crucial in these HG societies for preparing and responding to economic challenges.

\section{The transition to agriculture: a complex and long-term process}

The "Neolithic Revolution", as coined by Childe VG, ${ }^{21}$ was one of the major events in the history of humanity. Indeed, the shift from foraging to farming has been one of the most important events in the evolution of human societies. From Childe's seminal paper, archaeological records and studies have contributed to qualify his initial view: the "Neolithic revolution" has been replaced by a long and gradual process called the "Neolithic transition". Yet Childe was using the term Neolithic or Agricultural Revolution not in relation to speed but in relation to the revolutionary character of a change that no matter how rapid or how slow, transformed hunters and gatherers into shepherds and farmers. However, many of his successors have first interpreted the word "revolution" 22 as meaning rapid and radical. Indeed many believed that the shift from foraging to farming was rapid, irreversible and featured by the one shot adoption of the so-called "Neolithic package" including agriculture, husbandry, sedentism, stone axes and pottery. Since then all these interpretations have been challenged.

\section{From taming to domestication}

Although often characterized as rapid and the result of explicit human intention, domestication is a complex process along a continuum of human, plant, animal relationships that often took place over a long period and was driven by a mix of ecological, biological and human cultural factors. ${ }^{23}$ The relationship between humans and the nature involves two polar cases: a behavior in which human acts as a prey against the nature and on the other hand the domestication ${ }^{24}$ of plants and animals. Between these two polar cases, there exist a wide range of relationships including taming. The latter encompasses commensalism/mutualism to low-level management, while directed control over reproduction is associated with domestication. Taming clearly differs from domestication by contrast with the latter, it does not imply morphological or biological modification of species. Of course, some plants as well as some animals were tamed ${ }^{25}$ by huntergatherers before the Neolithic revolution.

For plants, a wide range of "technologies" may be considered as taming or wild resources management. They include fire-stick agriculture $^{4}$ to foster the growth of edible plants and to eliminate the others and also to attract game in the resulting meadows tending tubers, soil aeration, watering fields, semi-sowing or voluntary incomplete harvest of seeds. ${ }^{5}$ Until recently, all these proto-agricultural technologies were still used in many hunter-gatherer societies. The dog was probably the first animal to be domesticated, before the Neolithic period, even if it was not to provide food resources but mainly for helping humans in their hunting activities. Many other animals have been tamed: sheep, goat, cattle, pig and later horse, camel, llama (...). The reindeer ${ }^{6}$ is also a good example. During the Paleolithic period, it provided $80 \%$ of human diet. With the global warming

${ }^{4}$ For instance, in Australia, Aborigines used this technology since at least 9000 $\mathrm{BC}$

${ }^{5}$ In South California, once the seeds were harvested, the Kumeteyaay were burning the fields and thereafter they were sowing some of the seeds they had harvested.

${ }^{6}$ Rangifer tarandus. of the Holocene era, herds of reindeer migrated north to the arctic and subarctic regions where they are still living nowadays. In these regions, they have been tamed, providing meat, milk, hide and being also used for traction. However, they have never been domesticated they may return to the wild easily and even they may interbreed with those still living in the wild. The taming of plants and animals also fostered the geographical dispersion of these species. ${ }^{26}$ For instance, the wild pig living in many European Islands ${ }^{7}$ was introduced there by human during the Mesolithic period. All these taming activities of plants and animals developed by hunter-gatherers are corresponding to a proto-agricultural process. ${ }^{27}$ In some places the so-called "nuclear zones ${ }^{28}$ some of these taming activities have led to domestication, i.e. they have contributed to the Neolithic transition. It should however be noted that the process from taming to domestication was very long, as illustrated by Larson $\mathrm{G}$ et al. ${ }^{29}$ "In wheat, barley and rice, it took 2,000-4,000 years to fix the no shattering spikelet phenotype, a key indicator of cereal domestication". The evidence for a slow pace of domestication implies a cultural period in agricultural origins called pre-domestication cultivation. This period lasted for many centuries and has been inferred from evidence in the Near-East and China. Moreover, the length of this domestication process may be explained through the distinction ${ }^{8}$ between conscious and unconscious selection. Indeed, during the domestication process, conscious selection means that humans directly select for desirable traits. ${ }^{9}$ In contrast, the nonshattering seeds in cereals a trait which took 2000-4000 years to be obtained are thought to have arisen as a by-product of stalk-harvesting by sickles rather than by harvesting with the swinging basket. This case illustrates what is unconscious selection i.e. when traits evolve as a by-product of growth and natural selection in field environments or from selection of other traits.

\section{The required stream of innovations}

The domestication of plants and animals is a necessary but not a sufficient condition for the transition from foraging to an economy fully-based on agriculture to occur. Indeed, domestication can be seen as an innovation but many other innovations are required for the whole human population to be fed from agropastoralism activities. These additional innovations are respectively related to the production of food resources, their processing, storage and consumption. Even if we consider agriculture in its first stage, specific tools and techniques are required, for instance a digging stick to sow grains, an irrigation system, even if it is very basic or a sickle to harvest cereals. Once they have been harvested, domestic cereals require human activity, in the form of threshing and winnowing, to separate and disperse seeds. ${ }^{10}$ Once the seeds were obtained, they had to be stored in order to reduce the seasonal food risks. This requires some storage systems $\mathrm{s}^{30}$ such as small clay bins, larger storage pits or silos and granaries to prevent the seeds from rain, moisture, insects and rodents. Claypot and therefore the development of pottery, was necessary for the transportation and the conservation of grains and flour. Some plant processing instillations and tools were also necessary, such as mortars and pestles, to transform grains in flour. Even though the innovations listed above seem us to be very basic they were all necessary for a complete transition to agriculture. Therefore, the complete transition

${ }^{7}$ E.g. Ireland, the islands of the Baltic sea (Gotland, Bronholm and Saaremaa), Cyprus, Corsica and Sardinia.

${ }^{8}$ Darwin was the first to make explicitly this distinction.

${ }^{9}$ E.g. some Asian cultures had consciously selected glutinous grains of rice for their cuisine-prized trait.

${ }^{10}$ Wilds grasses generally disperse seeds by the presence of an abscission scar; however the latter is often lost in the process of domestication. 
to agriculture was a slow process. It seems that early agriculturalists for a long time were also involved in hunting and gathering. ${ }^{31}$ In the beginning, it is likely that little or no economic surplus was yielded by agriculture. It probably was in the nature of an income support measure, rather than a major addition to income. A major step forward in Mesopotamia was the development of irrigation around 5900 BC and around $4500 \mathrm{BC}$ the plough (called the ard) pulled by draught animals (donkeys or oxen) was introduced and the wheel was invented and used both for transport and making pottery. Heat-tolerant strains of wheat and barley were also selected. It was only with these additional and more advanced innovations that Mesopotamian farmers were able to produce food surplus.

\section{Explaining the transition to agriculture: push factors, pull factors or both?}

For more than one century, many explanations ${ }^{14,5}$ of the Neolithic transition have been given by archaeologists, anthropologists and pre-historians and more recently even by economists. Although it is widely agreed that this episode was crucial in human history, there is no unique explanation or theory of the Neolithic transition which therefore continues to attract discussions and intense debates. This transition to agriculture is viewed as the result of a few single agents that operate in the Near-East at the onset of the Holocene. Climate change, human population pressure and culturally driven alternatives, such as competitive feasting, are among numerous alternative explanations proposed in the literature.

\section{Climate and environmental changes}

Often, the transition to food production is explained by human adaptation to external shocks. Many external shocks are possible (e.g. wild animal extinction due to disease) but the most popular one currently is climate change and the induced transformations of ecosystems. This explanation is probably the most popular because past prevailing climate and ecosystems are nowadays perfectly known and measured by means of various modern techniques. Others features of the past such as the population size the degree of competition among neighboring tribes (...) are at best hypothesized.

One of the first and probably the most famous explanation of the Neolithic revolution based on climate change was proposed by Pumpelly $\mathrm{R}^{32}$ and popularized by Childe $\mathrm{VG}^{21}$ and is named the "Oases theory". In this theory, bands of HG were initially living in an environment able to satisfy their basic needs. However, a major climate change occurred; the transition from the Pleistocene to the Holocene, around 15 to 12.000 years $\mathrm{BC}$, was characterized by a global warming. With the end of the last ice age, some areas like the Sahara, which was initially a savannah where bands of HG were living, became an arid desert unsuitable for HG to live in. HG was therefore forced to migrate to the Near-East in places where life was still possible i.e. in oases and on the banks of large rivers. ${ }^{11}$ To survive in these places, they adapted their way of living and thus some of them the Natufians invented agriculture. The transition to agriculture results therefore from a logical sequence having some similarities with biological evolution theory. There is an exogenous shock climate change and then adaption and a process of natural selection that leads to agriculture i.e. to the emergence of a new human society, more developed than the previous ones.

${ }^{11}$ Such as the Nile, Euphrates and Tigris rivers.
Even though this theory is quite seductive, it does not explain why agriculture was not invented before this time. Indeed, many major climate changes have occurred since the appearance of Homo sapiens. Another shortcoming of this theory is that in the Near-East there is no evidence ${ }^{28}$ of major climate change for the period considered by Childe. Given this criticism, it has been argued recently ${ }^{33}$ that while the role of climate change in the evolution of human societies remained important, its contribution should be more qualified. Regions characterized by either too high or too low intertemporal climatic volatility are evolving more slowly, i.e. are experiencing a late onset of farming. Indeed, under static climatic conditions, HG is not forced to take advantage of the productive potential of their respective habitats and remain indefinitely in a hunter-gatherer regime as is assumed in the case of hunting and gathering "affluent societies". In addition occurrences of extreme environmental stress e.g. a return to semi-glacial or arid conditions - by eliminating the potential for farming, erode any accumulated human capital useful for agriculture, further delaying its adoption. It is therefore suggested that it is rather intermediate levels of intertemporal climatic volatility which fostered the transition from foraging to sedentary agriculture.

\section{Population Pressure}

Building on the ideas of Boserup E, ${ }^{34}$ who proposed that a growing population provided the impetus for the development of intensive agriculture, some archaeologists ${ }^{35}$ have long argued that huntergatherer economies continually evolved to accommodate exogenously growing populations, with the ever-expanding need for increased food supplies eventually leading to the adoption of farming. All approaches highlighting the role of population pressure in explaining the evolution of human societies are closely related to biological evolution theory. This affiliation is obvious in many publications..$^{36}$ In order to illustrate it, we may consider two stages in the economic development of any human society. The first one is the economy of subsistence. People are nomads; they get their food from hunting and gathering. Their main (unique) objective is to get enough food resources to satisfy their basic needs survival and reproduction and of course, to minimize their effort in doing so. They do not try to maximize their food procurement because their basic needs are satisfied and excess food resources would be wasted anyway (storage is not consistent with their nomadic way of life). If there is no population pressure, nothing is changing, i.e. this society may remain at this stage of economic development forever. However, as highlighted by T. Malthus, human population is growing faster than food resources provided by agricultural production and obviously, faster than food resources provided by foraging. So, once population pressure is introduced, so is the evolution of human society. An infinite motion starts, leading from foraging to farming society, then to the development of cities and the emergence of states. The underlying mechanism is the following: when population grows, the demand of food resources increases. To satisfy this additional demand, more food is gathered, new food resources are gathered while they were not before and people are trying to improve their labor productivity. All these changes in the food procurement strategy necessitate more cooperation among HG, more collective works, like groups contribution to larger-scale technologies or the formation of alliances to defend resources. Therefore, these changes imply the emergence of a class of non-food producers including chiefs, soldiers, traders, priests, craftsman (...). Although this class contributes, directly or not, to enhance the level of food resources, it also demands 
more food resources for their own consumption. Consequently the economy shifts to a second stage of development. In this economy, people, either $\mathrm{HG}$ or farmers are now maximizing their procurement/ production of food resources since a significant food surplus is henceforward required to satisfy the needs of people belonging to the class of non-food producers.

Population pressure critics argue that because many societies possess methods for controlling fertility via delayed marriage, prolonged lactation, induced abortion or infanticide, the population level needs never reach any Malthusian limits, exceed carrying capacity or feel any of the supposed effects of an imbalance of persons to resources. Some authors ${ }^{37}$ maintain that population pressure alone could not have played a critical role since there is no archaeological evidence of food crises prior to the development of agriculture.

\section{Unconstrained or voluntary adaptation}

The various theories of the Neolithic transition illustrated above and based on push factors, related either on climate change ${ }^{21}$ or on population pressure, ${ }^{36}$ are sharing a common thread: the transition to agriculture occurs when there is an excess demand for food resources. The latter can result from the negative impact of climate change on environment. It may also appear when population growth exceeds the carrying capacity of environment. We therefore see that despite the diverse contributions of the economic literature in explaining the Neolithic Revolution, population pressure, in most cases, is the ultimate driving force behind the transition to agriculture. However this force is considered as a constraint. Indeed, people must adapt their strategy to get food in order to satisfy the excess demand, otherwise they die (or at least some of them will die). In that case adaptation is considered as it is in biology, as a selection process, i.e. it is not decided by human societies. We claim that even if there are facing some constraints, like the ones related to the environment, human societies largely decide their evolution. In other words, adaptation is largely endogenous in the social evolution. Therefore, the Neolithic transition can be the result of voluntary human adaptation, i.e. of adaptation decided without constraint. In order to illustrate our point of view we recall that, as it is usual in the biological evolutionist approach, evolution is assumed to transform most of the time simple systems to complex domains and climate change is the perfect candidate for that purpose. As Childe assumed, the rise of agriculture could be humanity's response to a climate change resulting in a worse environment (altering the availability of food for humans). In that case, the resulting ecosystems are worse than before, with greater scarcity of food resources, for example as a result of a drought. In order to survive, i.e. to avoid starvation and death, HG must find new ways to get food and this may have led to the start of agriculture. ${ }^{21}$ However, the rise of agriculture could be humanity's response to a climate change resulting in a better environment. In that case, the resulting ecosystems support more abundant and diverse plants and animals. As a result, food procurement is easier for HG who therefore has more time for leisure and for experimenting with cultivation and the domestication of plants and animals. They may settle and have more children. ${ }^{12}$ These simple alternatives show that the agriculture onset can be the result of various external shocks (positive or negative) even when these shocks all arise from climate changes. More fundamentally, these alternatives demonstrate that in social evolution, opposite causes a negative or a positive shock may have the same consequence, i.e. may lead to the same evolution of human societies.

${ }^{12}$ This case can be illustrated by the way of life of complex HG (e.g. Natufians).

\section{Social competition and feasting}

Another case may also lead to agriculture from conscious adaptation, i.e. the excess demand for food resources can exist even if there is no population pressure. Indeed it is well known from Engel's laws about consumption that when the income increases, consumption shifts from primary to luxury goods. Such transformation may have occurred during the early Holocene. During that period, postglacial environmental transformation ${ }^{38}$ have led to the diversification of food resources, i.e. to the so-called "Broad-spectrum revolution" ${ }^{20}$ With more abundant and diverse food resources provided by the nature, HG may have chosen to consume more "luxury or prestige" goods, are these food resources or non food resources..$^{13}$ However, the production of these prestigious goods required more labor and therefore led to an excess demand for (primary) food resources. In others words, social competition for prestige in HG societies occurred endogenously, without constraint and it led, by means of conscious adaptation, to the rise of agriculture. ${ }^{14}, 39-40$

However this theory considers that farming was highly desirable from the earlier stages of agriculture development. In addition to the previous one, there are several others major problems with this theory about the Neolithic transition. One is that without explaining the underlying causes of competitive feasting, it fails to explain the development of agriculture and simply describes the process. Another problem comes from the fact that the surpluses needed for competitive feasting only became available as an outcome of food production not before.

\section{Nature and culture as factors leading to the establishment and sustainability of} agriculture

There is a debate among economists about whether economic development depends more on nature or on culture. This has led to the existence of two views or school of thoughts: for the first one, natural resource endowments (Biogeographic and geographic conditions) are the prime determinant of economic development while institutions are central to the second one. Of course each of these two views provides a different explanation of the Neolithic transition, i.e. of the establishment and sustainability of agriculture.

\section{The Role of Natural Resource Endowments}

After, ${ }^{41}$ the various levels of economic development among societies were widely explained by differences in geographic and biogeographic conditions. Geographic conditions ${ }^{42}$ include climate, latitude, soil, rain, orientation of continental axis (..); biogeographic conditions consist of edible plants and animals suitable for domestication and cultivation. They mainly refer to respectively largeseeded grasses and large mammals. It should be noted that geographic and biogeographic conditions do not have separate influence; they have a combined influence on plants and animals. Indeed, every plant or animal has certain habitat and environmental preferences. As such, they can only be cultivated and bred within their tolerance limits. ${ }^{43,15}$ Environmental factors such as temperatures, precipitation, solar radiation during the growth season, the length of the vegetation period (...) had overall influence on the crops cultivated and the animals bred.

${ }^{13}$ E.g. prestigious polished axes, furs of scarce animals, jewelry (made from amber or spondylus shell...)

${ }^{14}$ Many contributions in the literature are emphasizing the role of social competition or feasting to explain the Neolithic transition

${ }^{15}$ This phenomenon is called the minimum limiting factor 
Many subsequent works following Diamond's publication have tried to verify the importance of these conditions as factors influencing the occurrence of the Neolithic transition and in promoting the further economic development of the regions concerned. Some of the necessary conditions for agriculture to emerge are more easily identified when the diffusion of agriculture is studied rather than its origins. Indeed, in some areas the diffusion of agriculture has been hindered by geographical conditions (hills, mountains, rivers, seas). In some others areas, it has even been stopped by disease - in subSaharan Africa, cattle herding was not possible due to the presence of tsetse fly or by ecological barriers such as the one that existed in the Carpathian Basin ${ }^{44}$ where plants and animals reached in this place their tolerance limits and this stopped the diffusion of agriculture from the Balkans.

A central topic in these subsequent works ${ }^{45-48}$ following Diamond's publication is about the influence of the timing of the transition to agriculture on further economic development. Implicitly or not, these works consider that institutions only have second-order effects on the economic development.

\section{The role of institutions}

Following the definition given by North DC, ${ }^{49}$ institutions are "a set of rules, compliance, procedures and moral and ethical behavioral norms designed to constrain the behavior of individuals." In a later essay, ${ }^{50}$ he added: "If institutions are the rules of the game, organizations and their entrepreneurs are the players. Organizations are made up of groups of individuals bound together by some common purpose to achieve certain objectives. Organizations include political bodies, economic bodies, social bodies and educational bodies". On the basis of the previous definition, some authors ${ }^{51}$ argue that the major impact of the environment on economic development runs through its long-lasting impact on institutions. ${ }^{16}$ In other words, tropics, germs and crops do not affect country incomes directly other than through institutions. Among the various forms of the latter, the implementation of private property rights is considered ${ }^{52}$ to be one of the main necessary conditions for the Neolithic revolution to occur. To account for the difference of economic development among countries, various types of institutions have been defined $:^{53}$ inclusive ones favored economic growth whereas extractive ones lead - after a while - to crisis, economic and social collapses. The latter are called "extractive" because such institutions are designed to extract incomes and wealth from one subset of society (the commoners) to benefit a different subset (the elite).

\section{Mutual Causation Between Both Factors}

Even though natural endowments were important in enabling agriculture to become established one should not conclude that geographic or biogeographic determinism existed. Indeed, some resources were crucial at one point of time and of less importance later, due to innovation ${ }^{17}$ or because they became more abundant through trade. Similarly, when we talk about necessary ecogeographic conditions, we immediately think of edible plants and animals suitable for domestication. However, a critical resource may not necessarily be a food resource. For instance, during the Neolithic period agriculture was highly dependent on stone tools, especially on stone axes used for forest clearance. Although they were not a staple food, stone tools were therefore a critical resource for the agricultural

\section{${ }^{16}$ Including technologies.}

${ }^{17}$ Some stones (e.g. flint or obsidian) were valuable during the Neolithic period and used to make tools and weapons. However, with the introduction of metalworking, they became less valuable. system indeed some of these stones (especially obsidian) were traded on several hundred kilometers from their origin area ${ }^{54}$ which confirms that they were highly valuable.

Therefore, resource endowments were important in enabling agriculture to become established while they were not unimportant for its sustainability; institutions assumed increasing importance after agriculture was established and were also important for continuing development. In other words, both factors were important but their relative importance varied along the development path of the agricultural system. For instance, human capital accumulation and intergenerational transmission of knowledge were also necessary conditions; ${ }^{4}$ consequently a symbol system ${ }^{18}$ was required for that purpose.

According to a recent publication, ${ }^{55}$ this combined influence of both factors could be explained through the following mechanism. If we consider any center (e.g. Eurasia) where initially agriculture emerged, we must distinguish between the core and the periphery of this region. In the core (e.g. the Near-East), economic development was important at the beginning but has slowed afterwards. This is because the institutions implemented in the core were extractive. In the periphery (e.g. Northern Europe and Scandinavia), agriculture has been adopted by diffusion and the resulting economic development (including the traits defining "civilization") occurred later. Despite their later start, these countries are nowadays more developed compared to the Near-Eastern countries - because their institutions were inclusive from the beginning. Therefore, this third view assumes a degree of mutual causation between natural endowments and institutions. In other words, particular types of economic growth facilitated the development of particular institutions and social structures.

\section{Mechanisms bringing about the global spread of agriculture}

Current evidence suggests that the Neolithic materialistic culture was introduced to Europe via western Anatolia; this is the so-called neolithization process. ${ }^{56}$ All Neolithic sites in Europe contain the plants and animals initially domesticated in Southwest Asia: einkorn, emmer, barley, lentils, pigs, goats, sheep and cattle. Genetic data suggest that no independent domestication of animals took place in Neolithic Europe and that all domesticated animals were originally domesticated in Southwest Asia. It is therefore widely accepted that the onset of agriculture in the Near-East triggered a cultural change that diffused farming and associated technologies across Europe starting about 10,000 years ago. The information provided by archaeological remains and the trajectory of straight and short line paths suggest the estimated speed of agricultural spread was approximately 1 kilometer per year. ${ }^{8}$ Of course there were very significant regional variations in the rate of spread, e.g. unfavorable ecological and geographical factors caused a retardation of its spread to some part of Europe.

Despite these evidences, the Neolithic diffusion or the neolithization process of Europe has always been a controversial issue, ${ }^{57,19}$ not really solvable with known archaeological methods. Did people from the core invention area move en masse ${ }^{20}$ to other places bringing their innovations with them? Or did people from other places learn about

${ }^{18}$ It could be the spoken language and, for the elite, also the written language. ${ }^{19}$ It should be noted that until recently the same debate was present about the transition to agriculture in Japan. However, it is now widely agreed that the introduction of agriculture and the simultaneous replacement of the Jomon culture by the Yayoi were the result of a major incursion from mainland Asia. ${ }^{20}$ After Ammerman, A.J. and L. L. Cavalli-Sforza (1971), this massive folk migration is often called the "wave of advance". 
innovations from trade or other relationships such as intermarriage? In other words, a major debate ${ }^{58}$ in the study of earliest European farmers is whether they were colonists who settled in the major river valleys of North-Central Europe or whether they were local hunter-gatherers who adopted domestic plants and animals coming from the Near-East?

\section{The migrationist approach or the struggle for life}

Among these two alternative demographic scenarios proposed to account for the Neolithic transition, the first one was ${ }^{21}$ and still is ${ }^{59}$ the most popular in the academic literature. This scenario is called the demic diffusion model ${ }^{22}$ or, more usually, the migrationist approach. In the demic diffusion model, the spread of technologies involved a massive movement of people. The demic diffusion is a kind of replacement model. It posits that there was a significant migration of farmers from the Fertile Crescent into Europe. Given their technological advantages these migrants would have displaced or absorbed the less numerous hunter-gathering populace. If the demic diffusion model is the most popular explanation of the neolithization process, it is because it is based on a mechanism similar to competition among species - or natural selection present in biological evolutionary theory.

We know that the Neolithic revolution is featured by a transition from foraging to farming and that both economic systems - food procurement and food production - have advantages and drawbacks. However, agriculture has for a long time ago essentially taken over the world and hunting and gathering is now found only in very marginal and supposedly "backwards" area. Such situation is implicitly explained by the existence of a tradeoff between having more leisure and better nutrition versus simply being able to feed more mouths. Any given person may well choose to have a more varied and interesting diet and more free time than to be able to feed more people but otherwise be more miserable. If the latter option wins out in the end, most explanations in the academic literature are based on a vision which, implicitly or not, is an evolutionary process. As for the development of any given species (a plant or an animal), the development of human societies is assumed to be greatly determined by what strategies produce the most offspring. In any biological evolutionary competition, the strategy that produces the most children generation after generation will eventually win over strategies that allow the production of fewer children no matter how happy or unhappy those children are. So agricultural societies simply fed more people, allowed for larger families and so could push out, absorb or slaughter the hunter-gathering societies in the long run. Therefore, demographic pressure is generally considered to be the prime mover of the Neolithic expansion. As pointed out by Diamond J, ${ }^{41}$ "A final factor in the transition became decisive at geographic boundaries between hunter-gatherers and food producers. The much denser populations of food producers enabled them to displace or kill huntergatherers by their sheer numbers, not to mention the other advantages associated with food production (including technology, germs, and professional soldiers)".

\section{Neolithization by cultural diffusion}

Nevertheless, the migrationist approach has two shortcomings: it minimizes the role of cultural diffusion and overemphasizes the role of competition between HG and farmers. In doing so, it rejects

${ }^{21}$ This demographic scenario was already present in V. G. Childe (1936).

${ }^{22}$ This model has been first introduced by Ammerman A. J. and L. L. CavalliSforza (1984) the possibility that HG could have decided, without constraint, to adopt agriculture. However, the main rationale - which is the most often cited in the literature to explain the immigration of Neolithic farmers from the Near-East to Europe - i.e. the rapid population growth brought about the emergence and development of farming - can be challenged. Indeed, as pointed out by many authors, such as, ${ }^{10}$ "Archaeologically, there is no evidence for sustained and wideranging immigration that would support either the demic diffusion hypothesis or a major continent-wide migration". Moreover, the presumed competition between HG and farmers, which is implicit in the migrationist approach, does not find support in ecological evidence. Indeed, before the late Neolithic, there is no indication of extensive agriculture such as woodland clearances and environmental degradation i.e. no indication of competition between two economic systems that would have provided a rationale for relocation of $\mathrm{HG}$ societies. On the one hand, farmers settled exclusively in specific areas that were suitable for agriculture i.e. in fertile loess area and close to lakes or rivers, the latter being necessary for fields' irrigation. It should be noted that loess land was the best land for farmers while, with its dense lime stands, it was poor in game and yielded hardly any vegetable produce, i.e. was not consistent with HG economy. On the other hand, HG populations were much more attracted by coastal and lacustrine regions and along major rivers. Since there was no competition between these differing economic strategies, one can conclude that, "The arrival of these colonists does not resulted in any kind of direct violent conflict". ${ }^{60}$

Despite the previous conclusions, the total neolithization of Europe by cultural diffusion is not obvious. As stated previously (see section 2 ), in its early stages, the superiority of agriculture over foraging was uncertain, especially for complex HG societies. This has led to a third explanation of the spread of agriculture, mixing migration and imitation.

\section{The Integrationist Approach}

Most recent studies, ${ }^{59}$ as implied by archaeological data, show that cultural diffusion explains between 30 to $40 \%$ of the spread rate of the Neolithic transition in Europe. Thus, cultural diffusion cannot be neglected, but demic diffusion was the most important mechanism in this major historical process at the continental scale. ${ }^{23}$ Mixed models of diffusion combining migrationist diffusion and cultural diffusion are constitutive of the integrationist approach..$^{10}$ In this approach, the diffusion of agriculture results from various combinations of three mechanisms. Firstly, it relies on leapfrog colonization rather than on massive folk migration or demic diffusion. This denotes a selective colonization of an area by small groups, who target optimal areas for cultivation (usually, loess land). These groups are thus forming an enclave settlement among native inhabitants or HG. ${ }^{31}$ Secondly it considers frontier mobility, i.e. small-scale movement of population within contact zones between HG and farmers, occurring along the established social networks, such as trading partnerships, kinship lines and marriages alliances. Thirdly contact exists through trade within the framework of regional or extra-regional trading networks. ${ }^{61}$ These networks served as channels of communication through which innovations ${ }^{24}$ spread from farmers' communities to HG. Archaeologically, ethnographically and ecologically, the migrationist

${ }^{23}$ By contrast to South-East and Central Europe where both diffusions demic and cultural - were combined, the spread of farming in coastal west Mediterranean Europe now seems to have involved the rapid transport by sea of a complete package of Neolithic domesticates around 5400 BC by colonizing pioneer farmers.

${ }^{24}$ Such as cultivation of plants, domestication of animals, pottery $(\ldots)$ 
approach as well as the cultural one finds little evidence to explain the agricultural diffusion in Europe. Therefore, one can conclude to the superiority of the integrationist approach, as ${ }^{10}$ did: “...I would argue that the agricultural transition in Europe was, in the main, accomplished by the local Hunter-gatherer communities, with varying degrees of gene flow between hunter-gatherer communities and the settlements of Neolithic farmers. Enduring contact and exchange between the foraging and the farming communities led to the development of agricultural zones, manifested in the archaeological record by enduring cultural boundaries, for example...the Mesolithic/ TRB cultures of north temperate Europe".

\section{Conclusion}

In the early twentieth century, archaeologists were steadily accumulating data about past societies using a conceptual framework based on tools and technology. ${ }^{21}$ Most important contribution was to re-conceptualize the archaeological data in social terms and to identify a major social transformation the Neolithic Revolution that brought about new way of life and new form of society. Since Childe's publication, it is widely agreed that the transition from hunting and gathering to farming was one of the most important development in human history. Despite this universal agreement, many debates and controversies among scholars remain about the Neolithic revolution, its causes, features and consequences. These vivid controversies overwhelmed traditional debates between different schools of thoughts and between different scientific fields. They result from the fact that the transition to agriculture encompasses a wide range of causes and consequences that are themselves multidimensional economic, social, anthropological, ecological, biological, institutional and technical. Future researches on the Neolithic revolution should require, maybe more than on others topics, more interdisciplinary approaches. ${ }^{62-65}$

\section{Acknowledgements}

None.

\section{Conflict of interest}

Author declares there is no conflict of interest in publishing the article.

\section{References}

1. Harlan JR. Crops and Man. American Journal of Alternative Agriculture 1992;8(1):47-48.

2. Bowles S. Cultivation of cereals by the first farmers was not more productive than foraging. Proc Natl Acad Sci. USA 2011;108(12):4760-4765.

3. Berbesque JC, Marlowe FW, Shaw P, et al. Hunter-Gatherers Have Less Famine than Agriculturalists. Biol Lett. 2014;10(1):20130853.

4. Smith VL. Humankind in Prehistory: Economy, Ecology and Institutions In: Anderson TL and Simmons RT, editors. The Political Economy of Customs and Culture, Rowman \& Littlefield Publishers, USA; 1993; 157-184.

5. Svizzero S, Tisdell C. Theories about the Commencement of Agriculture in Prehistoric Societies: A Critical Evaluation. Rivista di Storia Economica. 2014;3:255-280.

6. Svizzero S. Population Pressure and the Transition to Agriculture. Global Journal of Human-Social Science. 2016;16(2):7-12.

7. Svizzero S. Transition to Farming More Likely in a Land of Plenty Research in Economic Anthropology. 2017;37.
8. Ammerman AJ, Cavalli LLS. Measuring the rate of spread of early farming in Europe. Royal Anthropological Institute of Great Britain and Ireland. 1971;6(4):674-688.

9. Ammerman AJ, Cavalli LL. The Neolithic Transition and the Genetics of Populations in Europe. Princeton Univ Press, USA; 1984. p. 194.

10. Zvelebil M. The agricultural transition and the origins of Neolithic society in Europe, Documenta Praehistorica. 2001;28:1-26.

11. Vizzero S. Farmers' Spatial Behaviour, Demographic Density Dependence and the Spread of Neolithic Agriculture in Central Europe, Documenta Praehistorica. 2015;42(8):133-146.

12. Lee RB, Vore ID. Man the Hunter, Adline, Chicago, USA; 1968.

13. Sahlins M. Stone Age Economics. Tavistock, England; 1974.

14. Weisdorf JL. From Foraging to Farming: Explaining the Neolithic Revolution. Journal of Economic Surveys. 2005;19(4):561-586.

15. Stock JT, Pinhasi R. Changing paradigms in our understanding of the transition to agriculture: Human bioarchaeology, behavior and adaptation. Human bioarchaeology of the transition to agriculture, John Wiley \&Sons Ltd, UK; 2011;1-13.

16. Bellwood P, Oxenham M. The Expansions of Farming Societies and the Role of the Neolithic Demographic Transition. In: Appel BJP, Yosef B, et al., editors.The Neolithic Demographic Transition and its Consequences, Springer, Dordrecht, Europe; 2008. p. 13-34.

17. Dow GK, Reed CG, Olewiler N. Climate reversals and the transition to agriculture. Journal of Economic Growth. 2009;14(1): 27-53.

18. Rosen AM, Collazo IR. Climate change, adaptive cycles and the persistence of foraging economies during the late Pleistocene/Holocene transition in the Levant. PNAS. 2012;109(10):3640-3645.

19. Stiner MC, Munro ND, Surovell TA. The Tortoise and the Hare. SmallGame Use, the Broad-Spectrum Revolution and Paleolithic Demography. Curr Anthropol 2000;41(1):39-79.

20. Flannery KV. Origins and ecological effects of early domestication in Iran and the near east. In Ucko PJ and Dimbleby GW, editors. The Domestication and Exploitation of Plants and Animals, Gerald Duckworth \& Co, London; 1969. p. 73-100.

21. Childe VG. Man makes himself. Watts, London; 1936. p. 271-272.

22. Greene K.V. Gordon Childe and the vocabulary of revolutionary change. Antiquity. 1999;73(279):97-109.

23. Diamond J. Evolution, consequences and future of plant and animal domestication. Nature. 2002;418(6898):700-707.

24. Price TD, Yosef OB. The Origins of Agriculture: New Data, New Ideas. An Introduction to Supplement. Current Anthropology 2011;52(S4): S163-S174.

25. Zvelebil M, Pluciennik M (2003) The role of food, agriculture, forestry and fisheries in human nutrition. Historical origins of agriculture. EOLSS Publishers LTD, France.

26. Zeder MA (2008) Domestication and early agriculture in the Mediterranean Basin: Origins, diffusion and impact. Proc Natl Acad Sci. USA 105(33):11597-11604.

27. Pryor F. From foraging to farming: The so-called "Neolithic Revolution". In: Alexander JF, editors. Research in Economic History, JAI Press, USA; 2004. p. 1-14.

28. Braidwood RJ. The agricultural revolution. Scientific American. 1960;203(3):130-148.

29. Larson G, Piperno DR, Allaby RG, et al. Current perspectives and the future of domestication studies. Proc Natl Acad Sci. USA; 2014;111(17):6139-6146. 
30. Kuijt I, Finlayson B. Evidence for food storage and predomestication granaries 11,000 years ago in the Jordan Valley. Proc Natl Acad Sci. USA; 2009;106(27):10966-10970.

31. Svizzero S, Tisdell C. The Persistence of Hunting and Gathering Economies. Social Evolution and History. 2015;14(2):3-25.

32. Pumpelly R. Explorations in Turkestan expedition of 1904: In Prehistoric Civilizations of Anau, Origins, Growth and Influence of Environment. Washington DC Carnegie Institution of Washington, USA; 1908.

33. https://ideas.repec.org/p/wil/wileco/2010-02.html

34. Boserup E. The conditions for agricultural growth: The economics of agrarian change under population pressure. Journal of Political Economy. 1967;75(2): p. 212.

35. Binford LR. Post-Pleistocene Adaptations. In: Binford SR, Binford LR, editors. New Perspectives in Archeology, Chicago, USA; 1968;313-341.

36. Johnson AW, Earle T. The Evolution of Human Societies: From Foraging Group to Agrarian State. Journal of the American Ethnological society. 2000;15(4):819-820.

37. Harlan JR. The Living Fields: Our Agricultural Heritage. The quarterly Review of Biology. 1996;71(4):597.

38. Roberts N. Postglacial environmental transformation. In: Bogucki P and Crabtree PJ, editors. Ancient Europe 8000 B.C.- 1000 A.D. Encyclopedia of the Barbarian World, Charles Scribners \& Sons, New York, USA; 2004. p. $126-131$

39. Bender B. Gatherer hunter to Farmer: a social perspective. World Archaeology. 1978;10(2):204-222.

40. Hayden B. Nimrods, Piscators, Pluckers and Planters: The Emergence of Food Production. Journal of Anthropological Archaeology. 1990;9(1):31-69.

41. Diamond J. Guns, Germs and Steel: the Fates of Human Societies. WW Norton, New York, USA; 1997.

42. Gallup JL, Sachs JD, Mellinger A. Geography and economic development International Regional Science Review. 1999;22(2):179-232.

43. Liebig J. Organic chemistry and its application to agriculture and physiology. In: Playfair and Gregory W, editors. Taylor and Walton Press, London; 1840.

44. Kertész R, Sümegi P. Theories, critiques and a model: why did the expansion of the Körös-Starcevo culture stop in the centre of the Carpathian Basin? The Mesolithic to the Neolithic, Archaeolinqua Press, Budapest, Europe; 2001;225-246.

45. Olsson O, Hibbs D. Geography, biogeography, and why some countries are rich and others are poor. Proc Natl Acad Sci. USA; 2004;101(10):3715-3720.

46. Olsson O, D Hibbs. Biogeography and Long-Run Economic Development. European Economic Review. 2005;49(4):909-938.

47. Chanda A, Putterman L. Early Starts, Reversals and Catch-up in the Process of Economic Development. Scandinavian Journal of Economics. 2007;109(2):387-413.
48. Putterman L. Agriculture, diffusion and development: Ripple effects of the Neolithic revolution. Economica. 2008;75(300):729-748.

49. North DC. Structure and Change in Economic History. WW Norton \& Co, New York, USA; 1981.

50. North DC. Economic performance through time. In: Eicher CK, Staatz JM, editors. International Agricultural Development, Johns Hopkins University Press, Baltimore, USA; 1998;78-90.

51. Easterly W, Levine R. Tropics, germs and crops: how endowments influence economic development. Journal of Monetary Economics. 2003;50(1):3-39.

52. North DC, Thomas RP. The First Economic Revolution. The Economic History Review. 1977;30(2):229-241.

53. Acemoglu D, Robinson J. Why Nations Fail: The Origins of Power, Prosperity and Poverty. Crown Publishers, New York, USA; 2012.

54. Tykot RH. Trade and exchange. In: Bogucki P, Crabtree PJ, editors, Ancient Europe 8000 BC-1000 AD Encyclopedia of the Barbarian World, Charles Scribners \& Sons, New York, USA; 2004. p. 65-71.

55. Olsson O, C Paik. A western reversal since the Neolithic? The long-run impact of early agriculture. University of Gothenburg; 2013: 1-66.

56. Price TD. Europe's first farmers: an introduction. Cambridge University Press, USA; 2000. p. 1-18.

57. Crawford GW. The transitions to agriculture in Japan. In: Gebauer AB, Douglas T, editors. Transitions to agriculture in prehistory, Prehistory Press, Madison, USA; 1992. p. 117-132.

58. Bogucki P. Recent Research on Early Farming in Central Europe Documenta Praehistorica. 2001;28:85-97.

59. Fort J. Synthesis between demic and cultural diffusion in the Neolithic transition in Europe. Proc Natl Acad Sci. USA; 2012;109(46):18669-18673.

60. Verhart LBM. Times fade away. The neolithization of the southern Netherlands in an anthropological and geographical perspective, Leiden, Europe; 2000.

61. Svizzero S. The Long-Term Decline in Terms of Trade and the Neolithization of Northern Europe. Scandinavian Economic History Review. 2015;63(3):260-279.

62. Yosef BO. Climatic fluctuations and early farming in West and East Asia. Current Anthropology. 2011;52(S4):S175-S193.

63. Bowles S, Choi JK. Coevolution of farming and private property during the early Holocene. Proc Natl Acad Sci USA. 2013;110(22):8830-8835.

64. Cohen MN. The Food Crisis in Prehistory: Overpopulation and the Origins of Agriculture, Yale University Press, New Haven. American Journal of Physical Anthropology. 1977;49(2):286-287.

65. Smith B. Low-Level Food Production. Journal of Archaeological Research. 2011;9(1):1-43. 